\title{
Studies of intestinal lymphoid tissue. XIV-HLA status, mucosal morphology, permeability and epithelial lymphocyte populations in first degree relatives of patients with coeliac disease
}

\author{
M N Marsh, I Bjarnason, J Shaw, A Ellis, R Baker, T J Peters
}

\begin{abstract}
Fifty two first degree relatives of patients with coeliac disease were investigated for HLA status, small intestinal permeability, and mucosal morphology together with the size of the intraepithelial lymphocyte pool and indices of lymphocyte activation, in an attempt to identify genetically determined markers of the disease. Thirty eight per cent of these subjects had increased intraepithelial lymphocyte populations and a highly significant association with HLA-DR3 compared with controls. Their intestinal permeability to ${ }^{51} \mathrm{chromium}$ labelled ethylenediamine tetraacetate was invariably normal and there was no evidence of abnormal mucosal architecture, increased crypt cell mitotic activity or lymphocyte 'activation'. Although increased intraepithelial lymphocyte counts clearly do not cause alterations in intestinal structure or function, it is likely that this parameter together with the HLA-DR3 status identifies a genetically determined predisposition to the disease which may only become clinically evident with larger doses of ingested gluten.
\end{abstract}

Department of Medicine (University of Manchester School of Medicine), Hope Hospital, Salford M N Marsh

Section of

Gastroenterology,

Clinical Research Centre,

Harrow

I Bjarnason

Department of Clinical

Gastroenterology

Broadgreen Hospital,

Liverpool

J Shaw

A Ellis

Laboratory of Computational Science, University of Salford

R Baker

Department of Clinical Biochemistry, Kings College Hospital,

London

T J Peters

Address for correspondence: Dr Michael N. Marsh, University Department of Medicine, Hope Hospital, Eccles Old Road, Salford, Manchester M6 8HD.

Accepted for publication 31 March 1989
Despite considerable investigation over many years, the pathogenesis of coeliac disease remains unexplained. ${ }^{1-4}$ One of the major obstacles to progress is that after a gluten free diet, most detectable abnormalities revert to normal, ${ }^{45}$ while in the few instances in which some kind of dysfunction remains, it is extremely difficult to exclude continued inadvertent ingestion of gluten, or perhaps, the effect of irreversible damage caused by long standing mucosal inflammation. . $^{1-9}$

In order to overcome some of these problems and to permit study of the early initiating approach is to study well treated patients exposed to gluten for relatively short times. ${ }^{3}$ An alternative is to study apparently unaffected close relatives of known propositi in order to identify isolated inherited abnormalities that do not by themselves lead to full expression of the disease, perhaps because of lack of other necessary interacting genetic, or environmental, factors.

Based on the latter approach, we have carried out a detailed investigation of a large number of first degree coeliac relatives who had been closely followed up in North West England for 10-20 years. The aim of this collaborative study was to pathogenic factors in this condition, one compare the HLA-DR status of such individuals with small intestinal permeability, mucosal morphology, the size of the intraepithelial lymphocyte pool and indices of epithelial lymphocyte 'activation', of which some may have importance in the pathogenesis of coeliac disease. ${ }^{3-5} 10-14$

\section{Methods}

FIRST DEGREE RELATIVES OF PATIENTS WITH COELIAC DISEASE

Of approximately 200 relatives from 28 families containing well documented coeliac disease propositi, 52 first degree subjects were selected, based on jejunal biopsies suitable for morphometric quantitation by computerised image analysis. They comprised 23 men (mean age 37 years; range: $18-78$ ) and 29 women (mean age 42 years; range: $17-72$ ). Those relatives with clinically symptomatic, or inapparent (latent), coeliac disease were, however, excluded from further study.

The majority of the 52 first degree relatives were healthy subjects without any significant previous medical history. Five had complained of recurrent mouth ulcers, another was on thyroxine replacement therapy and two had noninsulin dependent diabetes mellitus.

Apart from one individual with a previous history of diarrhoea, at the time of study, none had any gastrointestinal disturbance. For the 23 men and 29 women, respectively, there was no significant difference (Mean (SD)) in concentrations of haemoglobin, $14.4(1 \cdot 2)$ and 13.0 $(1 \cdot 8) \mathrm{g} / \mathrm{l}$ : serum folate, $6.4(2 \cdot 5)$ and $7 \cdot 2(4 \cdot 8)$ $\mu \mathrm{g} / \mathrm{l}$ : serum iron, $14.8(3 \cdot 1)$ and $16.6(6.9)$ $\mu \mathrm{mol} / \mathrm{l}$ : serum calcium, $2 \cdot 4(0 \cdot 16)$ and $2 \cdot 4$ $(0 \cdot 13)$, or serum $\operatorname{IgA}, 25(9)$ and $20(6) \mathrm{g} / \mathrm{l}$.

CONTROL SUBJECTS

(a) For evaluation of morphometric data, results were compared with those obtained for (i) 14 untreated coeliac patients and (ii) a group of 10 patient-control subjects referred for diagnostic gastrointestinal investigation to Department of Medicine at Hope Hospital: none of the latter was considered to have coeliac disease and jejunal morphology was judged normal by accepted criteria. ${ }^{15}$ (b) HLA-DR locus frequencies in the first degree relatives were compared with a sample of blood donors and members of staff from the same geographic area, as detailed below. 
HISTOLOGICAL TECHNIQUE

Jejunal biopsies were taken with a Watson capsule from the duodeno-jejunal flexure, quickly orientated, spread out on card, flooded

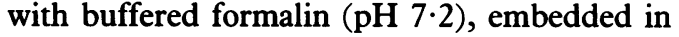
paraffin wax, sectioned at $5 \mu \mathrm{m}$ thickness in a plane perpendicular to the mucosal surface and stained with $\mathrm{H} \& \mathrm{E}$.

Eight to 10 serial sections were mounted per slide: alternate sections, provided their plane of sectioning was well oriented, were used for morphometric analysis. For this purpose, chosen sections were projected through a high resolution colour television (Sony) camera to a MOP-Videoplan $^{R}$ (Kontron-Reichert, Slough, England) computerised image analysis system. Photomicrographs were taken on Ilford (Ilford Ltd, Ilford, Essex, UK) $35 \mathrm{~mm}$ film as desired, and enlarged appropriately.

\section{QUANTITATIVE MORPHOMETRY}

\section{1: Surface and crypt epithelial volume}

In order to determine surface and crypt epithelial volumes $\left(\mathrm{V}_{\mathrm{SE}}: \mathrm{V}_{\mathrm{CR}}\right)$ per specimen, profiles of relevant sectioned epithelium were outlined by the scribing cursor together with the length of underlying muscularis mucosae. For valid comparison, measurements were standardised to a constant test area $\left(100 \times 100=10^{4} \mu \mathrm{m}^{2}\right)$ of muscularis mucosa. The relative coefficients of variation for each series of measurements per specimen were $<10 \%$ : these calculations are automatically included in the print-out of the measuring programme supplied by the manufacturers.

Total crypt cell mitotic figures per specimen, as a reflection of crypt cell proliferative activity, were also quantitated with reference to $10^{4} \mu \mathrm{m}^{2}$ muscularis mucosae.

\section{2: Size distribution of intra-epithelial lymphocytes} Based on previous work, ${ }^{13} 16$ the mean size of intraepithelial lymphocytes per specimen was expressed in terms of nuclear diameters. The circumference of nuclear profiles was traced with the cursor from which crude diameters were computed. Sufficient observations to ensure a constant mean (SD) were incorporated: on average, 80-100 lymphocyte nuclear profiles per specimen were required to meet these criteria.

The distribution of the crude profile diameters was corrected for 'lost' profiles, ${ }^{11}{ }^{17}$ and the mean of this revised distribution was further corrected for imperfect 'non-sagittal' sectioning ${ }^{18}$ by multiplying by $4 / \pi$. In this way, the true nuclear diameter $\left(D_{N}\right)$ of a representative sample of intraepithelial lymphocytes per specimen was obtained.

\section{3: Determination of intraepithelial lymphocyte population size}

In order to calculate the actual number of cells (N) within a defined tissue volume $(\mathrm{V})$, the mean diameter (such as $D_{N}$ ) must be calculated in order to determine 'effective section thickness' (EST) which is determined from the relationship
$\left(t+D_{N}\right)$ where $t$ is actual section thickness $(5 \mu \mathrm{m}) .^{1920}$ The absolute number of intraepithelial lymphocytes contained within an epithelial volume $\left(V_{S E}\right.$ or $\left.V_{C R}\right)$ with respect to a $10^{4} \mu \mathrm{m}^{2}$ test area of muscularis mucosa was determined by enumerating lymphocyte profiles within surface, or crypt, epithelium overlying a length of muscularis equivalent to $\left[10000 / \mathrm{D}_{\mathrm{N}}+\right.$ 5)] $\mu \mathrm{m}$. Nuclear profiles were preferred in calculating EST because they are more usually circular in outline compared with cytoplasmic profiles, and thus more accurately measured. ${ }^{1316}$ The proportion of 'immunoblastoid' intraepithelial lymphocytes with $D_{N}>6 \mu m^{1619}$ per specimen was calculated from the distributions obtained in (2) above. The number of metaphase-figures counted in a total of 3000 epithelial lymphocytes per specimen was expressed as per cent mitotic index. ${ }^{1421}$

INTESTINAL PERMEABILITY

Of the 52 subjects included in this study, 26 gave informed consent to undergo an intestinal permeability test with ${ }^{51} \mathrm{Cr}$-EDTA, assessed by determining the $24 \mathrm{~h}$ urinary excretion of the probe molecule as described previously. ${ }^{89}$ Ethical approval for the use of this test was given by the appropriate local research committees.

\section{HLA TYPING}

HLA-DR typing was performed by a cytotoxicity technique based on an adaptation of a two-colour fluorescence method. ${ }^{22}$ The panel of available sera defined seven specificities (DR1-DR7). The controls were 168 staff members or blood donors from the same geographic areas.

\section{STATISTICAL ANALYSIS}

Statistical analyses were performed with the SPSS package. Group means were compared with the Mann-Whitney $U$ test, a $p$ value of $<0.05$ being taken as significant. The Spearman correlation coefficient was used to compare epithelial lymphocyte numbers with (i) surface epithelial volume or (ii) ${ }^{51} \mathrm{Cr}$-EDTA urinary excretion. Differences between antigen frequencies were examined by Fisher's exact (two-tailed) test as previously described. ${ }^{23}$

\section{Results}

INTRAEPITHELIAL LYMPHOCYTE

POPULATIONS $\left(\mathrm{N}_{\mathrm{V}, \mathrm{SE}}: \mathrm{N}_{\mathrm{V}, \mathrm{CR}}\right)$ :

Values for $\mathrm{N}_{\mathrm{V} \text {,SE }}$ were positively skewed for relatives of patients with coeliac disease (skewness $+1 \cdot 18$, which differed significantly (p $<0.01)$ from zero). Thus all values were logarithmically transformed, the normalised distribution having a recalculated skewness of $-0 \cdot 10(p=N S)$.

In comparison with $\mathrm{N}_{\mathrm{V}, \mathrm{SE}}$ for 20 disease controls, the 52 first degree coeliac disease relatives were arbitrarily divided into subgroups 1 and 2. In group $1, \mathrm{~N}_{\mathrm{V}, \mathrm{SE}}$ fell below the upper 
Figure 1: Right hand panel shows a marked increase in small, non-mitotic intraepithelial lymphocytes $(E L)$ within normal villi (arrows in a group $2 C D$ relative), compared with appearances in a group 1 mucosa (left hand panel). (Magnifications: $\times 1925$ : Insets, $\times 67$ )

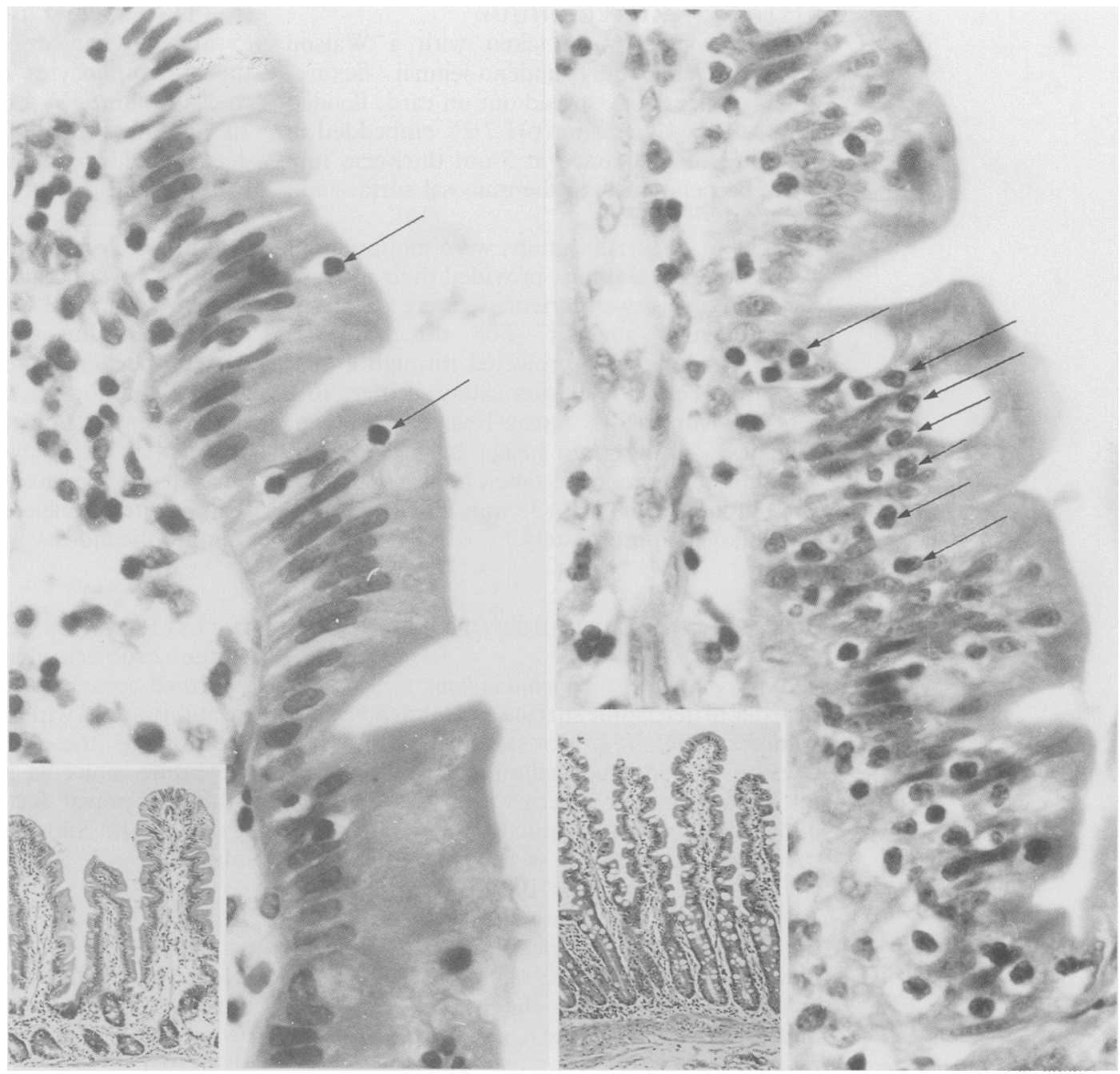

$95 \%$ confidence limits of the control sample ( 240 \pm 93 ) while in group 2 , comprising $38 \%$ relatives studied, $\mathrm{N}_{\mathrm{V}, \mathrm{SE}}$ exceeded these limits (630 (122)) as shown in representative micrographs (Fig 1). Corresponding values for absolute intraepithelial populations in the crypts $\left(\mathrm{N}_{\mathrm{V}, \mathrm{CR}}\right)$ were, for group 1 subjects 21 (8), and for group 2 subjects with raised villous epithelial lymphocyte populations, 34 (18) (differences NS). Neither was there any difference in crypt cell mitotic activity (per $10^{4}{\mu \mathrm{m}^{2}}^{2}$ muscularis mucosae) between group $1(6 \cdot 3(3 \cdot 3))$ and group $2(6.6(4.5))$ individuals. Thus the increment in intraepithelial lymphocytes was confined to villus epithelium only (group 2 relatives).

\section{SIZE DISTRIBUTION AND MITOTIC} ACTIVITY OF INTRAEPITHELIAL

LYMPHOCYTES

There wàs no difference in the mean nuclear diameter $\left(D_{N}\right)$ of intraepithelial lymphocytes between the ciisease-controls $(5 \cdot 0(0.2) \mu \mathrm{m})$ and coeliac disease relatives $(4 \cdot 6(0 \cdot 3) \mu \mathrm{m})$. Mean values for $D_{N}$ between group $1(4.5(0.3) \mu \mathrm{m})$ and group $2(4.4(0.3) \mu \mathrm{m})$ coeliac disease relatives were also identical (Fig 2). The percentage of large lymphocytes $\left(D_{N}>6 \mu \mathrm{m}\right)$ in the disease-controls and in each subgroup of coeliac disease relatives were similar and considerably less than found in patients with untreated coeliac disease $^{14} 19$ (Fig 2). The mitotic activity (sample of 3000 intraepithelial lymphocytes per specimen) determined for each subgroup of coeliac relatives did not exceed the $0 \cdot 2 \%$ seen in patients with untreated coeliac disease. ${ }^{141921}$ Thus, based on size and mitotic activity, there was no evidence of lymphocyte 'activation' within either group of coeliac relatives.

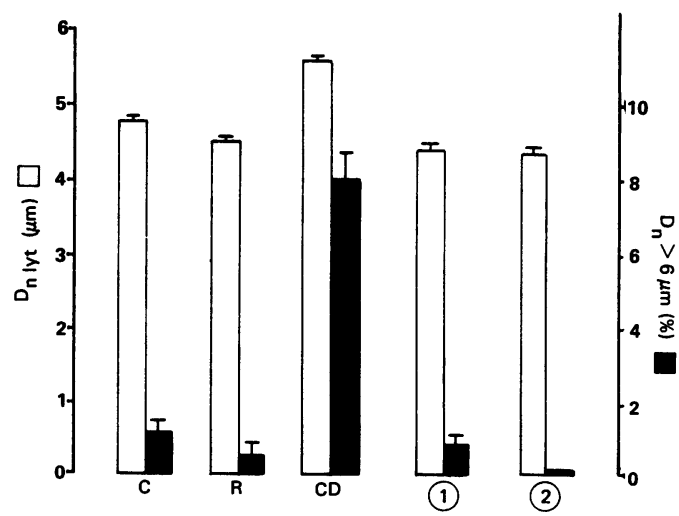

Figure 2: Mean nuclear diameters of intraepithelial lymphocytes (Dn, Lyt - left hand axis) and the percentage $D_{N}$ $>6 \mu \mathrm{m}$ (right hand axis) in controls $(C), C D$ relatives $(R)$ and their subgroups, 1 and 2, compared with a group of untreated coeliacs $(C D)$. The coeliac relatives either considered together, or as subgroups based on lymphocyte populations, do not differ from the controls, whereas untreated coeliac patients display 'activated' $E L$ with an increased mean nuclear diameter, and increased proportion $>6 \mu \mathrm{m}$ diameter. 


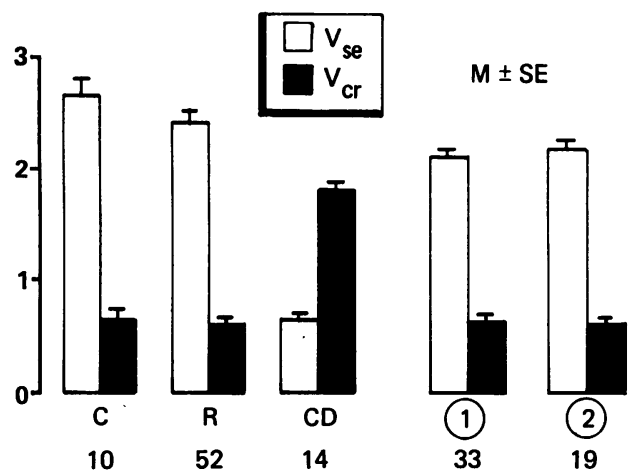

Figure 3: Villus ( $V_{S E}$ : open bars) and crypt ( $V_{C R}$ : shaded bars) epithelial volumes (expressed on vertical axis $\times 10^{6} \mu \mathrm{m}^{3}$, per $10^{4} \mathrm{um}^{2}$ muscularis mucosae) between controls $(C)$, first degree relatives $(R)$ and their subgroups, 1 and 2 , are not significantly different, in contrast to the marked reduction in surface epithelium and increased crypt volumes characteristic of untreated coeliac $(C D)$ patients.

\section{SURFACE AND CRYPT EPITHELIAL}

VOLUMES ( $\left.\mathrm{V}_{\mathrm{SE}}: \mathrm{V}_{\mathrm{CR}}\right)$

No significant differences were observed between surface, or crypt, epithelial volumes ( $\mathrm{V}_{\mathrm{SE}}, \mathrm{V}_{\mathrm{CR}}$ per $10^{4} \mathrm{~mm}^{2}$ muscularis mucosa) between groups 1 and 2 relatives (Fig 3 ). There was no relationship between the size of the intraepithelial lymphocyte $\left(\mathrm{N}_{\mathrm{V}, \mathrm{SE}}\right)$ population in epithelium and villus morphology (Fig 4), despite the increased number of lymphocytes in group 2 relatives.

URINARY EXCRETION OF"CR-EDTA

The percentage $24 \mathrm{~h}$ urinary excretion of the orally-administered test dose of ${ }^{51} \mathrm{Cr}$-EDTA was similar in group $1(2 \cdot 1(0 \cdot 9))$ and group $2(2 \cdot 3$ $(0 \cdot 7))$ subjects and did not exceed the upper limit of normal $(3 \%)$ for this test as determined in earlier studies. $^{82425}$ No significant correlation was demonstrated between $\mathrm{N}_{\mathrm{V}, \mathrm{SE}}$ and percent-

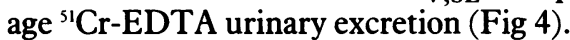

\section{HLA-DR FREQUENCIES AMONG COELIAC}

\section{RELATIVES}

There was a significant difference in the frequency of DR3 antigen in Group 2 subjects $(82 \%)$ with a high intraepithelial lymphocyte population compared with controls $(26 \%)$ (Fisher's exact test (two-tailed) $\mathrm{p}=0.02$ ). Group 1 individuals, in which the frequency of $\mathrm{DR} 3^{+}$ was $50 \%$, did not differ significantly from controls.

\section{Discussion}

In this study we measured jejunal mucosal morphology and intraepithelial lymphocyte populations, small intestinal permeability and HLA-DR status of first degree relatives of patients with coeliac disease. A large proportion $(38 \%)$ of individuals was identified with a high intraepithelial lymphocyte population which arbitrarily divided the patients into two groups. The results show that the increase in epithelial lymphocytes (in group 2 relatives) was not associated with structural mucosal abnormalities or functional disturbances, as reflected by absence of bowel symptoms, nutritional defects or increased mucosal permeability.

In previous studies we investigated the use of ${ }^{51} \mathrm{Cr}$-EDTA as a measure of mucosal permeability, and as a simple means of identifying inflamed intestine. ${ }^{82+25}$ The $24 \mathrm{~h}$ urinary excretions of ${ }^{51} \mathrm{Cr}$-EDTA in this study fell within the upper limit of normal (3\% of ingested dose) except in occasional subjects who were equally distributed between group 1 and 2 relatives. Morever the subjects with increased permeability did not have any other features in common, and drug induced causes for these moderate rises were excluded, ${ }^{26}$ although we were less able to insure against alcohol ingestion. ${ }^{2}$

If coeliac disease were due wholly, or in part, to a specific inherited defect in intestinal permeability, then some evidence of that defect might also be expected among close relatives. The absence of such defect suggests that altered permeability is therefore not a major risk factor in pathogenesis, so that the persistence of abnormal ${ }^{\text {s1 }} \mathrm{Cr}$-EDTA tests in patients in remis$\operatorname{sion}^{825}$ is more likely to be the result of continued (inadvertent) ingestion of trace amounts of gluten, insufficient to affect overt mucosal regeneration but capable of inducing local inflammatory mediator release.

In earlier studies of coeliac families, ${ }^{1012}$ emphasis was placed on the identification of relatives with coeliac disease, although such additional cases were only uncovered in approximately one-third of all families studied. Moreover, approximately $50 \%$ of these new cases were asymptomatic or 'latent', and we were careful to

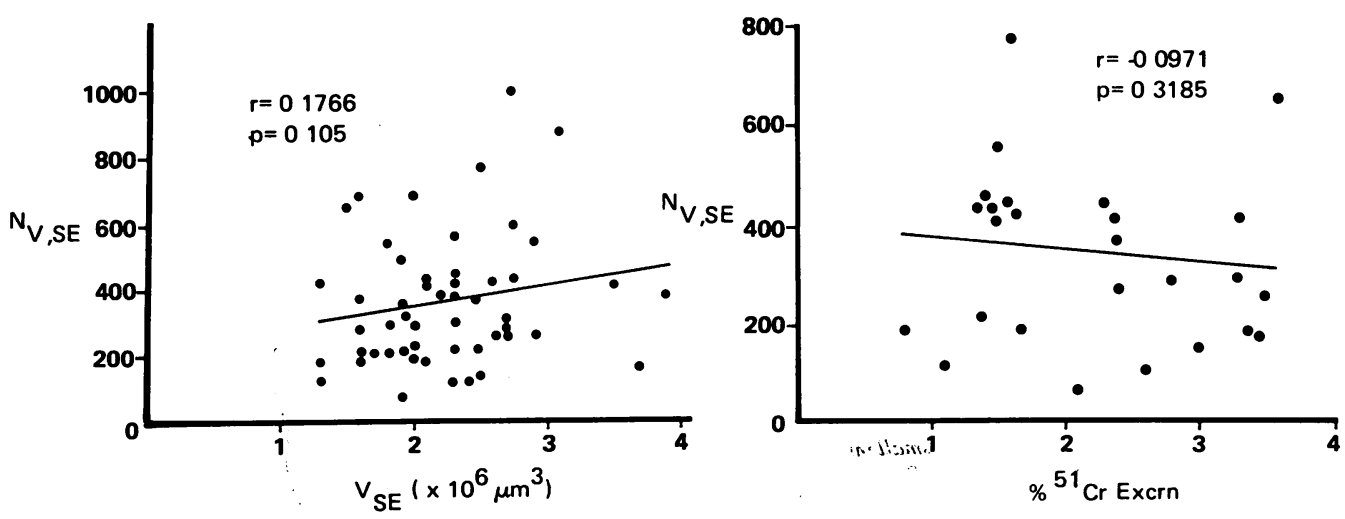

Figure 4: For the entire group of relatives (left hand panel) studied there is no significant correlation between absolute number of surface epithelial lymphocytes $\left(N_{V, S E}\right)$ and surface epithelial volumes $\left(V_{S E}\right)$. There is no significant relationship between surface epithelial lymphocytes $\left(N_{V}, S E\right)$ and surface epithelial volumes $\left(V_{S E}\right)$. There is no significant relationship between
epithelial lymphocyte populations $\left(N_{V, S E}\right)$ (right hand panel) and percentage excretion of "Cr-EDTA in the 26 relatives tested. 
exclude all such individuals from this study. In comparison with previous studies, however, we were left with a significant proportion $(38 \%)$ of first degree relatives, predominantly of DR3 phenotype, whose mucosae revealed a markedly increased intraepithelial lymphocyte population. Furthermore, these individuals were identified in every pedigree examined, and not restricted to one-third of all families as is characteristic for fully developed 'flat' mucosal lesions, whether associated with symptoms or not. If all our group 2 first degree relatives were to progress and develop overt disease, then the familial prevalence rate for coeliac disease in the North-West region would considerably exceed the consistent $\pm 10 \%$ rate recorded in the UK, ${ }^{12} 28{ }^{29}$ Irish Republic, ${ }^{11}$ USA $^{1030}$ and other parts of the world. ${ }^{3132}$ It is therefore evident that these individuals appear to have a non-progressive mucosal abnormality.

The significance of the lymphoid infiltrate in group 2 relatives is unclear. They were assumed to be ingesting a normal diet unlike experimental subjects ${ }^{33}{ }^{34}$ in whom gluten loading may result in an accumulation of intraepithelial lymphocytes. What is evident from this study is that the presence of an increased number of intraepithelial lymphocytes is neither causally related to increased mucosal permeability, nor to any structural abnormality. In this respect these observations parallel earlier studies when we fed treated coeliac patients with small, graded doses of Frazer's fraction III, resulting in dose dependent rises in intraepithelial lymphocytes without accompanying mucosal deterioration: similarly, these lymphocytes were small and non-mitotic. ${ }^{35}$ This is in keeping with other data suggesting that gluten induced accumulation of lymphocytes within epithelium plays no role in mucosal damage, because (i) intraepithelial lymphocytes may increase in number after dietary gluten restriction ${ }^{136}$ (ii) crypt cells in untreated coeliac disease, despite a five-fold increase in intraepithelial lymphocytes, ${ }^{16}$ are evidently unimpaired in their hypertrophic response or ability to generate goblet, argentaffin and Paneth cells and (iii) many gluten sensitised individuals with dermatitis herpetiformis ${ }^{37}$ carry raised lymphoid infiltrates in their villi without evidence of functional or structural enteropathy. Collectively, all these observations suggest that intraepithelial lymphocytes alone are unlikely to play a role in initiating, or sustaining, mucosal damage throughout the entire 'gluten-sensitive spectrum'. It would be interesting to challenge such relatives with gluten, however, to confirm that they do indeed have a subclinical form of the disease, and that mucosal flattening would necessarily ensue.

MNM and TJP were supported by the Medical Research Council, UK and MNM also by North West Regional Health Authority.

1 Scott $\mathrm{H}$, Brandtzaeg P, Thorsby E, Baklien K, Funsa, Ek $J$. Mucosal and systemic immune response patterns in Ek J. Mucosal and systemic immune respon

2 Kagnoff MF. Coeliac disease: genetic, immunological and environmental factors in disease pathogenesis. Scand 7 Gastroenterol 1985; 20: (suppl 114): 45-54.

3 Marsh MN. Coeliac Disease. In: Marsh MN, ed. Immunopathology of the small intestine. London: Wiley, 1987: 371-99.

4 Peters TJ, Bjarnason I. Coeliac syndrome: biochemical mech anisms and the missing peptidase hypothesis revisited. Gut 1984; 25: 913-8.
5 Marsh MN. Immunocytes, enterocytes and the lamina propria: An immunopathological framework of coeliac disease. pria: An immunopathological framew

6 Peters TJ, Jones PE, Wells G. Analytical subcellular fractionation of jejunal biopsy specimens: Enzyme activities organelle pathology and response to gluten withdrawal in patients with coeliac disease. Clin Sci Mol Med 1978; 5 285-92.

7 Bruce SE, Bjarnason I, Peters TJ. Human transglutaminase: demonstration of activity, enzyme kinetics and substrate specificity with special relation to gliadin and coeliac disease. Clin Sci 1985; 68: 573-9.

8 Bjarnason I, Peter TJ, Veall N. A persistent defect in intestina permeability in coeliac disease demonstrated by a ${ }^{5} \mathrm{Cr}-$ labelled EDTA absorption test. Lancet 1983; i: 323-5.

9 Bjarnason I, Peters TJ, Levi AJ. Intestinal permeability: clinical correlates. Dig Dis 1986; 4: 83-92.

10 MacDonald WC, Dobbins WO, Rubin CE. Studies of the familial nature of celiac sprue using biopsy of the small intestine. NEngl F Med 1965; 272: 448-56.

11 Mylotte M, Egan-Mitchell B, Fottrell PF, McNichol B $M c C a r t h y, C F$. Family studies in coeliac disease. $Q \mathcal{F} \mathrm{Med}$ 1974; 171: 359-69.

12 Stokes PL, Ferguson R, Holmes GKT, Cooke WT. Familia aspects of coeliac disease. $Q \mathcal{F} \mathrm{Med} 1976 ; 180: 567-82$.

13 Niazi NM, Leigh RJ, Crowe P, Marsh MN. Morphometric analysis of small intestinal mucosa. I - Methodology, epithelial volume compartments and enumeration of interepithelial space lymphocytes. Virchows Archiv [Pathol Anat] 1984; 404: 49-60.

14 Marsh MN. Studies of intestinal lymphoid tissue. III Quantitative analysis of epithelial lymphocytes in the small intestine of human control subjects and of patients with coeliac sprue. Gastroenterology 1980; 79: 517-25.

15 Rubin CE, Brandborg LL, Phelps PC et al. Studies of celiac sprue. I - The apparent identical and specific nature of the duodenal and proximal jejunal lesion in celiac disease an idiopathic steatorrhoea. Gastroenterology 1960; 38: 28-49.

16 Marsh MN, Hinde J. Morphometric analysis of intestinal mucosa. III - The quantitation of crypt epithelial volumes and lymphoid cell infiltrates, with reference to celiac sprue mucosae. Virchows Archiv [Pathol Anat] 1986; 409: 11-22.

17 Giger H, Riedwyl H. Bestimmung der GröBenverteilung von Kugeln ans Schnittkreisadien. Biometr Deitschr 1970; 12: $156-65$.

18 Weibel ER. Stereological Methods. Vol 1. New York: Academic Press, 1979.

19 Marsh MN. Functional and structural aspects of the epithelia lymphocyte, with implications for coeliac disease and tropical sprue. Scand f Gastroenterol 1985; 20: (suppl 114): 55-75.

20 Marsh MN, Mathan M, Mathan VI. Studies of intestina lymphoid tissue. VII - The secondary nature of lymphoid cell "activation" in the jejunal lesion of tropical sprue. $A m \mathcal{F}$ Pathol 1983; 112: 302-12.

21 Marsh MN. Studies of intestinal lymphoid tissue. IV - The predictive value of raised mitotic indices among jejunal epithelial lymphocytes in the diagnosis of gluten-sensitive enteropathy. $\mathcal{F}$ Clin Pathol 1983; 35: 517-25.

22 Van Rood JJ, van Leuwen A, Ploem JS. Simultaneous detection of two cell populations by two color fluorescence and application to the recognition of $B$ cell determinants. Nature 1976; 262: 795-7.

23 Ellis A, Taylor CJ, Remmy-Dillon M, Woodrow JC, McConnell RB. HLA-DR typing in coeliac disease: evidence for genetic heterogeneity. BrMed f 1984; 289: 1571-753.

24 Bjarnason I, O'Morain C, Levi AJ, Peters TJ. Absorption of "Chromium-labelled ethylenediamine tetra-acetate in inflammatory bowel disease. Gastroenterology 1983; 85: 318-22.

25 Bjarnason I, Marsh MN, Price A, Levi AJ, Peters TJ Intestinal permeability in patients with coeliac disease and dermatitis herpetiformis. Gut 1985; 26: 1214-9.

26 Bjarnason I, Williams P, Smethurst P, Peters TJ, Levi A . Effect of non-steroidal anti-inflammatory drugs and prostaglandins on the permeability of the human small intestine. Gut 1986; 27: 1292-7.

27 Bjarnason I, Ward K, Peters TJ. The leaky gut of alcoholism: possible route of entry for toxic compounds. Lancet 1984; possible

28 Rolles CJ, Myint TO, Sin WK, Anderson CM. Family study of coeliac disease. [Abstract] Gut 1974; 15: A827.

29 David TJ, Ajdukiewicz AB. A family study of coeliac disease. f Med Genetics 1975; 12: 79-82.

30 Falchuk ZM, KatZ AJ, Schwachman H, Rogentine GN Strober W. Gluten-sensitive enteropathy: genetic analysi and organ culture study in 35 families. Scand $\mathcal{F}$ Gastroenterol 1978; 13: 839-43.

31 Shipman RT, Williams AL, Kay R, Townley RRW. A family study of coeliac disease. Aust $N Z 7$ Med 1975; 5: 250-55.

32 Sagaro E, Jiminez N. Family studies of coeliac disease in Cuba. Arch Dis Child 1981; 56: 132-3.

33 Weinstein WM. Latent celiac sprue. Gastroenterology 1974; 66: 489-93.

34 Doherty M, Barry RE. Gluten-induced mucosal changes in subjects without overt small bowel disease. Lancet 1981; i:

35 Leigh RJ, Marsh MN, Crowe P, Kelly C, Garner V, Gordon D. Studies of intestinal lymphoid tissue. IX - Dose dependent, gluten-induced lymphoid infiltration of coeliac dependent, gluten-induced lymphoid inflitration of coelia

36 Cooke WT, Holmes GKT. Coeliac disease. Edinburgh: Churchill-Livingstone, 1984

37 Fry L, Seah PP, McMinn RMH, Hoffbrand AV. Lymphocytic infiltration of epithelium in diagnosis of glutensensitive enteropathy. $\mathrm{BrMed} \mathcal{F}$ 1972; ii: $371-4$. 